\title{
Comparative Analysis of Satellite and Regulatory based Gas Flare Volumes in the Niger Delta Region
}

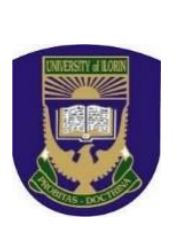

\author{
P. N. Ndunagu ${ }^{1 *}$, O. F. Joel ${ }^{1}$, A. A. Oji ${ }^{2}$ \\ ${ }^{1}$ World Bank African Center of Excellence in Oil Fields Chemical Research, Rivers State, Nigeria. \\ ${ }^{2}$ Department of Chemical Engineering, University of Port Harcourt, Rivers State, Nigeria.
}

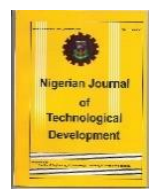

\begin{abstract}
Associated gas flaring leads to severe environmental issue, and the importance of effective monitoring and accurate recording of this operation has been a subject of discussion in the petroleum industry. This research used statistical methods to compare the flare volume of both Regulatory Agency records and Satellite-based estimates to determine the accuracy and reliability of estimates. Seven prolific offshore oilfields from the Niger Delta region were considered for this research and the monthly records of flare volume for 2016, 2017, 2020 and 2021 were used to investigate the comparative relationship that exists. The result revealed that the mean flare volumes of four oilfields (Agbara, Bonga, Erha and Usan) did not differ significantly but Abo and Akpo oilfields revealed that estimates from the satellite were significantly greater than the regulatory reports, while the estimates from Agbami oilfield supported the contrast. The Pearson correlation analysis also revealed that a moderately strong positive relationship exists between the estimates for the sampled oilfields. The study further examined the discrepancies between both methods of gas flare measurements and proffered solutions on how these discrepancies could be resolved and recommended a strategy for monitoring natural gas venting.
\end{abstract}

KEYWORDS: Remote sensing, routine gas flaring, Niger Delta, gas flare measurement, visible infrared, radiometer suite.

\section{INTRODUCTION}

Flaring of Associated gas in the Petroleum Upstream industry has led to serious environmental, regulatory and economic issue in Nigeria. Flaring in this context is the burning of hydrocarbon gases or vapours in oil production or gas handling facilities due to technical, financial and regulatory reasons. Associated gas flaring is considered the largest flaring source globally with smaller volumes coming from oil refineries, natural gas processing plants, coal mines and landfills. Gas flaring at oil production has been classified into three major types; Routine, Safety and Non-routine gas flaring (GGFRP, 2016). Routine gas flaring is a significant contributor to global warming and there is a campaign by the World Bank and relevant stakeholders to end routine gas flaring by 2030 (World Bank, 2021). The routine gas flaring of associated gas is illustrated in Figure 1. Measurement or estimation of flare gas on-site has traditionally been a challenge because of the varying nature of the flare gas flow rate, composition, richness of the gas and presence of impurities. There are various methods to measure these flare volumes, but two most important methods are the Continuous measurement method and Estimation methods. The continuous measurement method involves recording data uninterruptedly at the flare site. Orifice and Venturi meters are sometimes considered for this purpose but they are less tolerant to liquid and dirt that may be present in the stream. However, Ultrasonic flow meters, as recommended by (Mylvaganam, 1989) are suitable for flare volume measurement because of their excellent rangeability or turndown ratio and are not affected by changes in the composition of the gas stream. Generally, continuous measurements equipment are expensive to purchase and install in facilities, therefore they are not usually employed. Estimation methods are the most common ways of assessing flare volumes in oil and gas facilities without continuous metering. These methods include the use of process simulation, mass balance and use of Gas to Oil Ratios (GORs); though they are quite simple to estimate, the error margin may vary significantly if not correctly applied (GGFRP, 2016).

Ndunagu (2021) explained that there are various levels of flare gas monitoring, and improving data at these levels will 


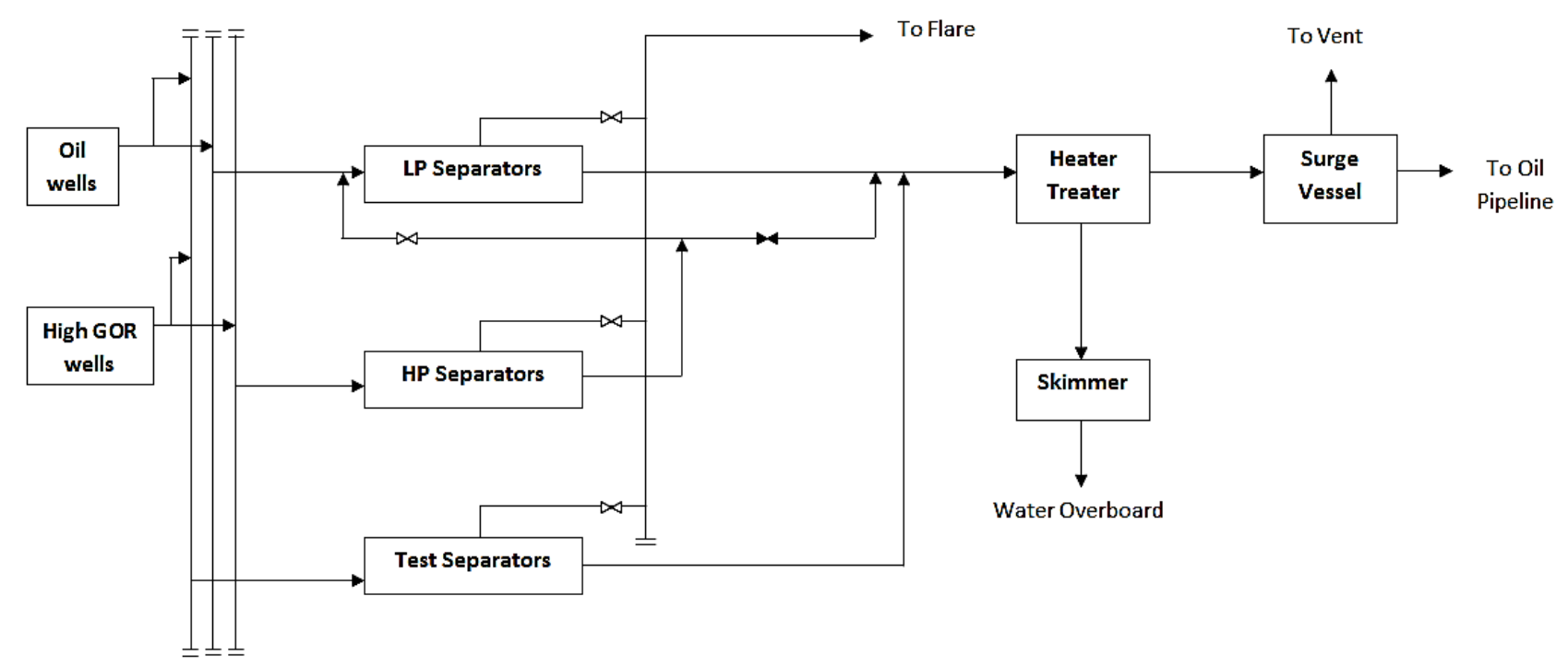

Figure 1: Schematic diagram of an Oil production facility with a routine gas flare.

ensure quality data for effective and unbiased enforcement of flaring regulations and penalties. A significant challenge is the self-reporting of flare volumes, which oilfield operators can significantly under-report when using either continuous or estimation methods in Texas (Willyard and Schade, 2019). This issue can be in the form of malfunctioning meters, inaccurate and untimely reporting of flare volumes. Therefore, improving flare data's reliability, completeness, and accuracy is essential as a crucial prerequisite to flare reduction and investments.

\section{A. Remote Sensing for Gas Flare Monitoring}

With improvement in information acquisition technology, space satellite remote sensing can be used to detect and quantify gas flaring in different locations on the Earth's surface (Elvidge et al, 2009; Zhang et al, 2019). Remote sensing is a method of information acquisition of a phenomenon without making physical contact with the source of observation. Early remote sensing gas flaring identification and estimation were carried out using the Along Track Scanning Radiometer (ATSR) on-board the European Space Agency (ESA) satellites (ERS-1, ESR-2 and ENVISAT) and the Defence Metrological Satellite Program Operational Linescan System (DMPS-OLS) (Casadio et al, 2011). These early remote sensing technologies had limitations such as relatively low temporal resolution, unavailability of nighttime data, cloud cover and scanline correction error (Anejionu et al, 2013). The Moderate Resolution Imaging Spectroradiometer (MODIS) was later developed based on night-time thermal imagery, and data from these devices have been used to identify and estimate flaring activities in the Niger Delta (Anejionu et al, 2014). Since 2012, the Visible Infrared
Imaging Radiometer Suite (VIIRS) on-board the Joint Polar Satellite System (JPSS) satellites have provided higher resolution images of the Earth's surface. The VIIRS is a multispectral imaging technology that can measure light in various spectral bands and frequencies beyond visible light, such as infra-red and ultraviolet. These polar-orbiting, nongeosynchronous satellites include the Suomi NPP and NOAA-20 (JPSS-1) used for metrological and environmental observations of the Earth's surface, as shown in Figure 2. Three more JPSS satellites will be launched between 2022 and 2031 as part of the JPSS space program (JPSS, 2021).

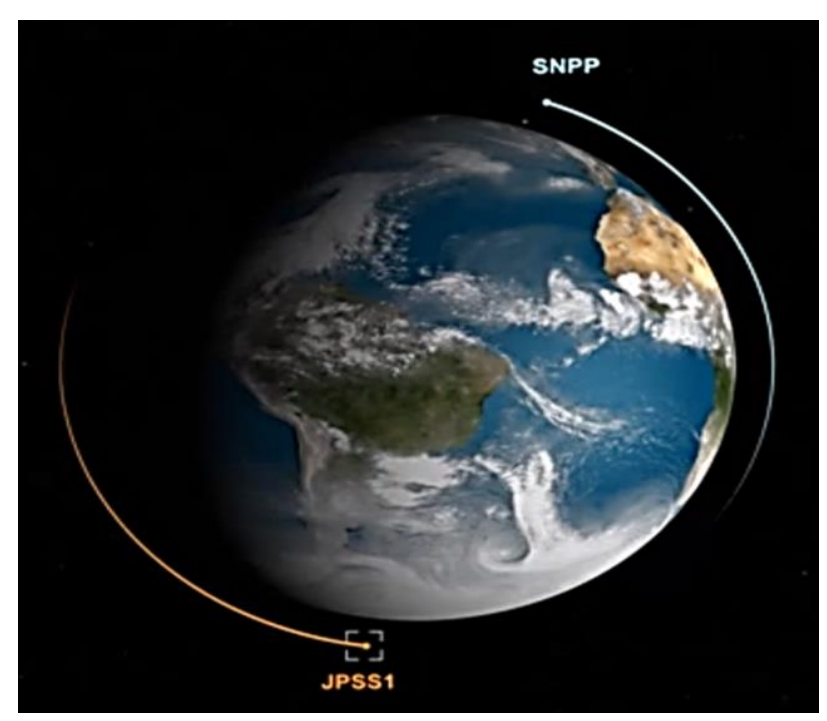

Figure 2: Illustration of S-NPP and NOAA-20 (JPSS1) satellites in a sun-synchronous orbit (NASA, 2018). 
In comparison with the MODIS, the thermal band of VIIRS has a 375-meter resolution per pixel while the MODIS has 1000 meters resolution per pixel, making it well suited for monitoring fire or gas flaring activities (NASA, 2015). The JPSS satellites circle the Earth from the North Pole to the South Pole, crossing the Equator 14-times daily, thereby providing complete coverage of the Earth twice a day. According to (Brandt, 2020), offshore facilities (platforms and floating production units) are much simpler to identify as they occur at only a limited number of points and characterize as they have a well-defined boundary compared to onshore facilities.

VIIRS on-board the JPSS satellites are operated uniquely and offer a substantial advantage for observing gas flaring and active fire sites. According to (Coffey, 2012), multispectral imaging can combine two to five spectral imaging bands with large bandwidth to form a single optical system. In essence, visible ( 0.4 to $0.7 \mu \mathrm{m})$, near-infrared (NIR; 0.7 to $1 \mu \mathrm{m}$ ), shortwave infrared (SWIR; 1 to $1.7 \mu \mathrm{m}$ ), mid-wave infrared (MWIR; 3.5 to $5 \mu \mathrm{m}$ ) or long-wave infrared (LWIR; 8 to $12 \mu \mathrm{m})$ bands can be combined into one system. At night, the VIIRS records data in three near to short-wave infrared channels (M7, M8 and M10) designed for daytime imaging. During this time, sunlight is unavailable, and images identified in these channels are combustion sources. Nighttime data collection is further improved with the M11 band for quantification and detection of flare gas (Elvidge et al, 2015).

Examination of temperature versus sources of combustion conducted by (Elvidge et al, 2015) concluded that there are majorly two groups. The low-temperature set $(800-1200 \mathrm{~K})$ is dominated by biomass burning such as forest fires, while gas flares dominate the high-temperature set (above 1450K) with most of the flares in the $1700-1800 \mathrm{~K}$ range. From Figure 3 below, the peak radiant emission from gas flares is located at $1.61 \mu \mathrm{m}$ wavelength of the SWIR while $4 \mu \mathrm{m}$ wavelength (MWIR) is widely used by satellites for other fire detections and large flare detection because they fall at the trailing edge of gas flare radiant emission.

Sharma et al (2017) performed a comparison of multiple satellite-based thermal data with their corresponding night fire algorithms for fire detection, temperature, and flare area measurement, concluded that the VIIRS Night Fire (VNF) algorithm performed significantly better than other night fire algorithm products. Data such as temperature and flare area measurement generated by the VNF can then be used to determine the thermal radiant energy, which can be converted to flare gas volumes. Regulators and policymakers can then use this information to make an unbiased assessment of flaring in the region of investigation. Studies by (Hodgson, 2018) showed the potential of the VNF satellite data in quantifying gas flaring from Nigerian Oil Fields compared with official regulatory data from Nigeria National Petroleum Corporation (NNPC) from 2013 - 2016 at individual flow stations. It was further observed that satellite-based flare estimates are significantly greater than state regulatory reports (Collins, 2018; Lee, 2019; Leyden, 2019), and as such, the discrepancies need to be resolved.

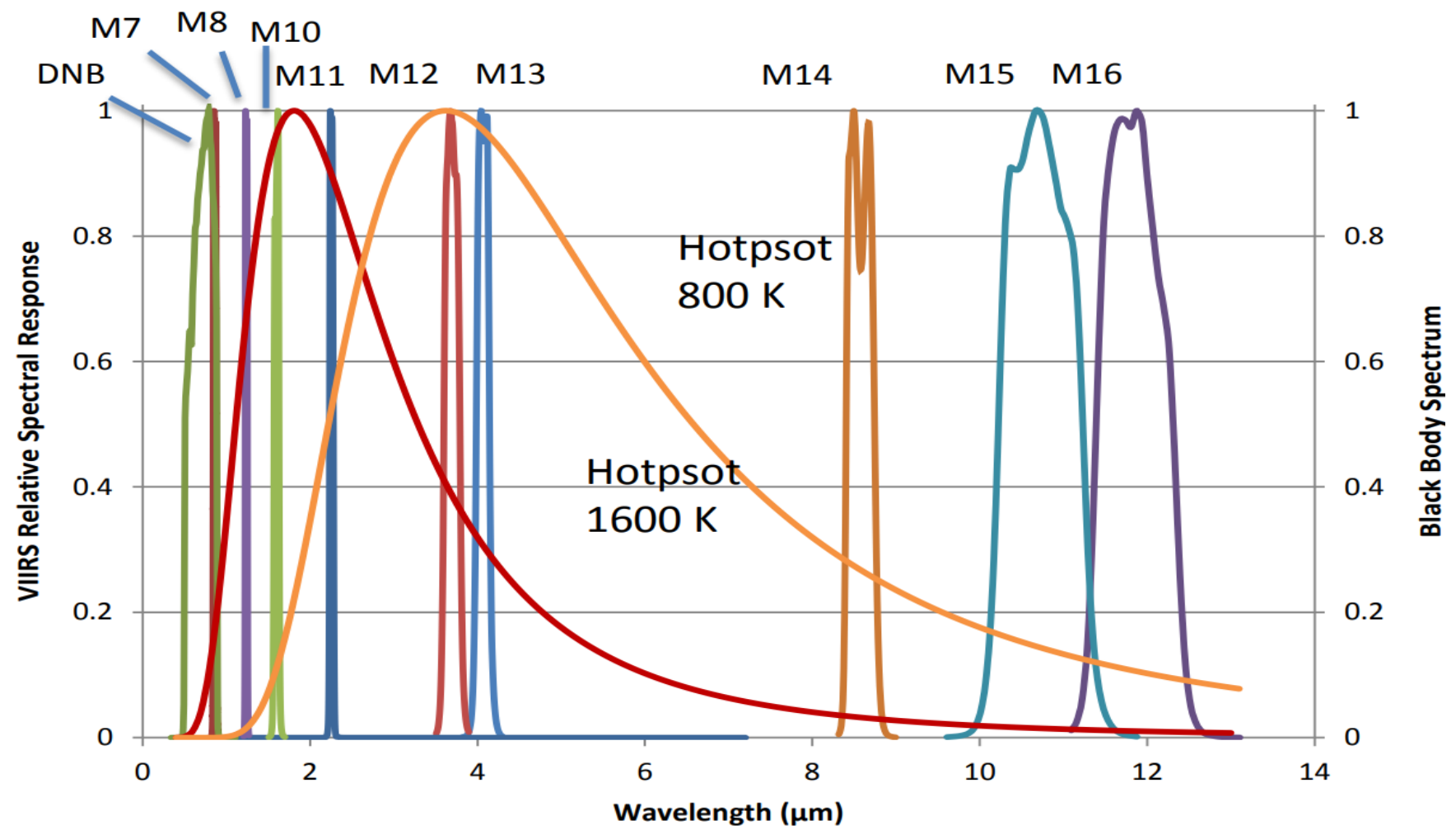

Figure 3: Relative spectral response of Visible Infrared Imaging Radiometer Suite (VIIRS) bands and the Planck curve of a typical gas flare at 800K and 1600K - Day-night band (Elvidge et al, 2015) 


\section{THEORETICAL ANALYSIS}

A. Estimating Flare Gas Volumes from the VIIRS Satellite Data

The gas flares detected under the multiple spectral bands can be modelled in a Planck curve using the flare radiance emission. The flare temperature is derived by using Wien's Displacement Law:

$$
T=b / \lambda_{\max }
$$

where $T$ is the temperature in kelvin $(\mathrm{K}), b$ is the Wien's displacement constant $=2897.8 \mathrm{~K}^{*} \mu \mathrm{m}$ and $\lambda_{\max }$ is the wavelength of the peak radiant emissions.

Next, the flare radiant heat per unit area is calculated from the temperature estimate using the Stephan-Boltzmann equation.

$$
\mathrm{J}=\sigma \varepsilon \mathrm{T}^{4}
$$

where $J$ is the radiant heat per unit area $\left(\mathrm{Watts} / \mathrm{m}^{2}\right), \varepsilon$ is the flare emissivity (assumed constant) and $\sigma$ is the StefanBoltzmann constant.
To estimate the Total Radiant Energy (W), flare surface area $\left(\mathrm{m}^{2}\right)$ has to be estimated. This surface area is determined by taking the ratio of the height $\left(\mathrm{h}_{\mathrm{o}}\right)$ observed in the flare Planck curve and the height of the curve that would result from the flare that fills the area of the detector footprint $\left(h_{d}\right)$ multiplied by the detector footprint. The illustration of the heights considered is shown in Figure 4.

Flare surface area $(\mathrm{S})=\mathrm{h}_{\mathrm{o}} / \mathrm{h}_{\mathrm{d}} \times$ detector footprint a

Total Radiant Heat (Watts)

$$
\begin{aligned}
& \mathrm{RH}=\mathrm{J} \times \mathrm{S}^{\mathrm{D}} \\
& \mathrm{D}=\text { Nonlinear correction }
\end{aligned}
$$

The flare volumes are then estimated from the radiant heat using the calibration obtained from the Regression Through the Origin (RTO) between radiant heat (RH) and flare volumes reported in billion cubic meters (BCM) by Cedigaz, as shown in Figure 5. The correlation coefficient of the relationship is 0.85 .

Satellite flare volume estimate $=$

$$
0.0281 \text { (Slope) } \times \mathrm{RH}
$$

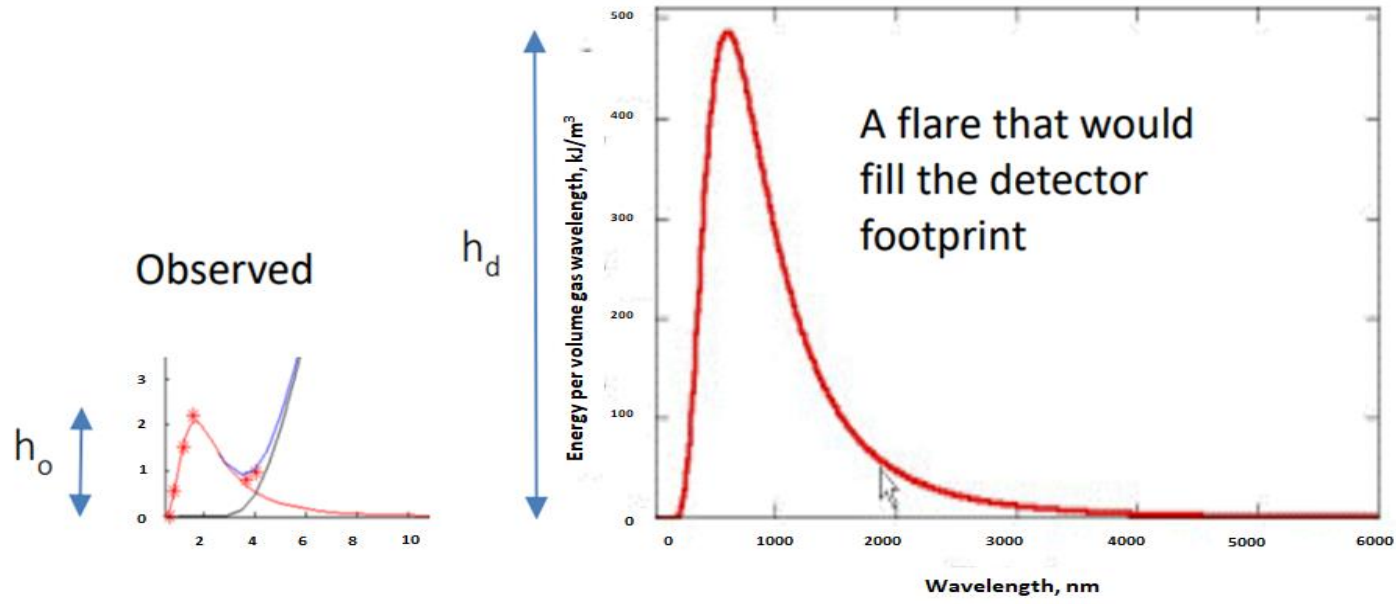

Figure 4: Ratio of observed height and detector footprint height of Planck curve (World Bank, 2020).

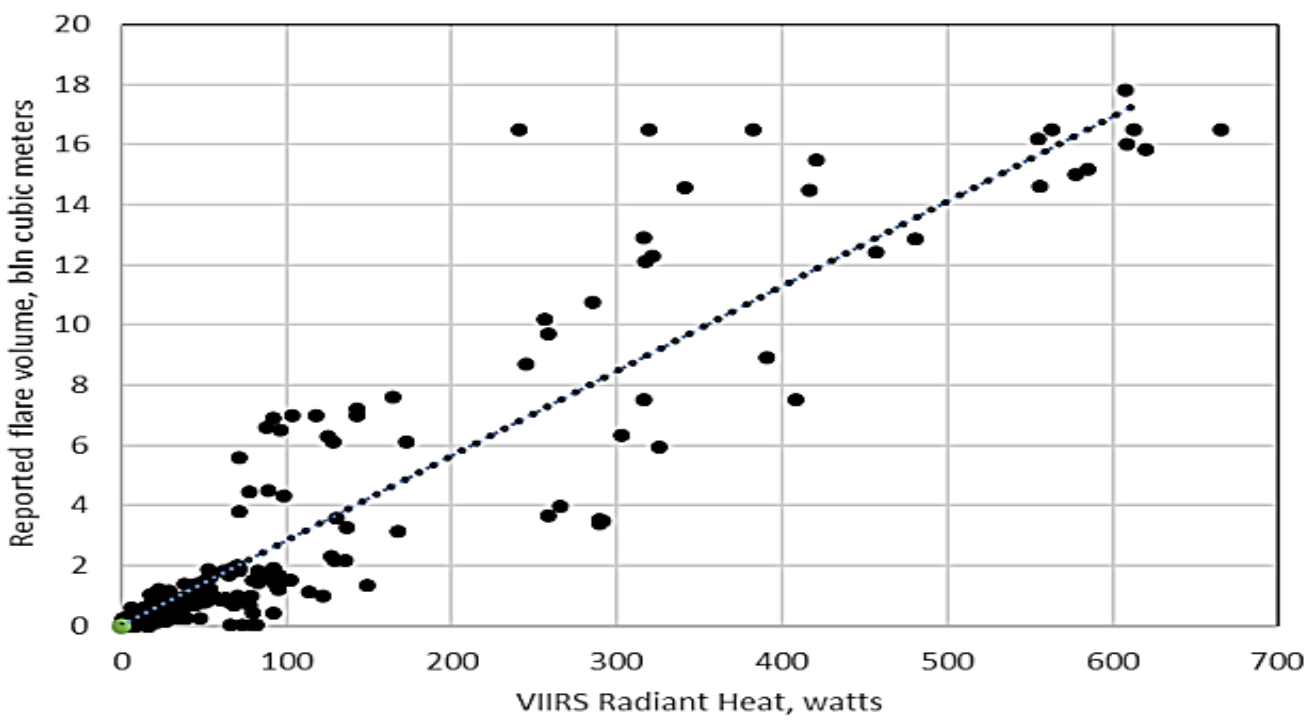


Recent studies in calibration include using dedicated flare sites to validate and modify existing calibration and investigate the linear relationship between radiant heat and flare volume and the impact of variation in gas composition. Also, machine learning and other sophisticated algorithms have been employed to enhance the quality of the results generated.

Research studies have compared regulatory reports with satellite-based reports regarding gas flaring and concluded that satellite-based data are significantly higher than reported data. This research aims at comparing statistically the selected Niger Delta offshore oil fields flare volume from both regulatory and satellite-based estimates to determine their accuracy and reliability.

\section{METHODOLOGY}

\section{A. Sampling Technique}

The population considered for this research is Nigeria's offshore oil fields. Seven (7) fields were purposively sampled due to their spare distribution for ease of identification, clear flare boundary definition, prolific oil production and availability of flare volume data. A summary of the fields is shown in Table 1.

Table 1: Summary of selected offshore oil fields.

\begin{tabular}{lllll}
\hline S/N & $\begin{array}{l}\text { Offshore } \\
\text { Field }\end{array}$ & $\begin{array}{l}\text { Production } \\
\text { Type }\end{array}$ & Operator & OML \\
\hline 1 & Agbara & $\begin{array}{l}\text { Production } \\
\text { Platform }\end{array}$ & Eni & 116 \\
2 & Abo & FPSO & Eni & 125 \\
3 & Agbami & FPSO & Chevron & $127 / 128$ \\
4 & Akpo & FPSO & Total & 130 \\
5 & Bonga & FPSO & Shell & 118 \\
6 & Erha & FPSO & Exxon & 133 \\
& & Mobil & \\
7 & Usan & FPSO & Exxon & 138 \\
& & & Mobil & \\
\hline
\end{tabular}

\section{B. Sources of Data}

The data used for this research were secondary data sourced from the following:

\section{1) Nigeria gas flare tracker (NGFT)}

Monthly flare volumes from different oil fields in the Niger Delta were considered from March 2012 to April 2021 (approximately nine years) from the NGFT website in .xlsx format. The volumes were reported in thousand Standard cubic feet (Mscf) and later converted to Million Standard cubic feet (MMscf). In the NGFT flare map, the various oil fields in the Niger Delta region have already been identified by a geographical boundary. It is an initiative of the National Oil Spill Detection and Response Agency (NOSDRA) which uses satellite remote sensing technology.

\section{2) Skytruth}

Skytruth is an independent environmental watchdog that uses satellite remote sensing technology to monitor the impact of various forms of pollution on the Earth. The annual flare volumes were obtained from identified oil fields with figures reported in BCM and converted to MMscf from 2012 to 2020 in .xlsx format.

3) Nigerian national petroleum corporation (NNPC)

The NNPC is the entity through which the Nigerian government participates in the petroleum industry. NNPC keeps and publishes monthly reports regarding flare gas records as part of the Extractive Industries Transparency Initiative (EITI). The monthly records considered were from January 2016 to December 2017 and January 2020 to April 2021. Monthly records of 2018 and 2019 were not used because they were not available at the time of writing. Also, the annual gas flare volumes were obtained from the NNPC Annual Statistical Bulletin (ASB) and the period considered was 2012 to 2020 .

\section{4) Nigerian Oil and Gas Industry Annual Report (NOGIAR)- 2018}

The Department of Petroleum Resources (DPR) is the government agency responsible for regulating upstream activities in Nigeria. The annual flare volumes of the Niger Delta expressed in "Mscf" from 2012 to 2018 were also considered for this research work.

\section{5) The World Bank}

The World Bank's Global Gas Flaring Reduction Partnership (GGFRP) developed a Global Gas Flaring Tracker that monitors the flaring activities of different countries. The data is based on the two US NOAA satellites in space and interpreted with the assistance of the Payne Institute for Public Policy at the Colorado School of Mines (World Bank, 2019). The period under consideration is 2012 to 2020 and the values are reported annually in BCM.

\section{Method of Data Analysis}

1.) Flare site identification based on geospatial data using NGFT (with already identified fields) and Skytruth with confirmation from Google Map. Flare volume data extraction and collection from sources based on available records. The flare volumes estimates were then aligned (monthly and yearly) based on their corresponding oil fields and periods.

2.) Hypothesis tests were developed and analysed statistically using a Paired t-Test using Minitab 19 with a significant confidence level of $\alpha=0.05$. Diagnostic test was carried on the various data sets to quality check for outliers, missing data and normality. Finally, Pearson correlation was applied to determine the degree of linear association of the datasets considered.

\section{RESULTS AND DISCUSSION}

\section{A. Comparing Annual Gas Flare Volumes in Nigeria}

Presently, there is no generally accepted method of gas flare volume estimation, but the VIIRS satellite monitoring seems to have a wider acceptance primarily due to the uniformity, consistency and availability of the information across the entire globe. Although remote sensing has these advantages, it is vital to calibrate their estimates with reports 


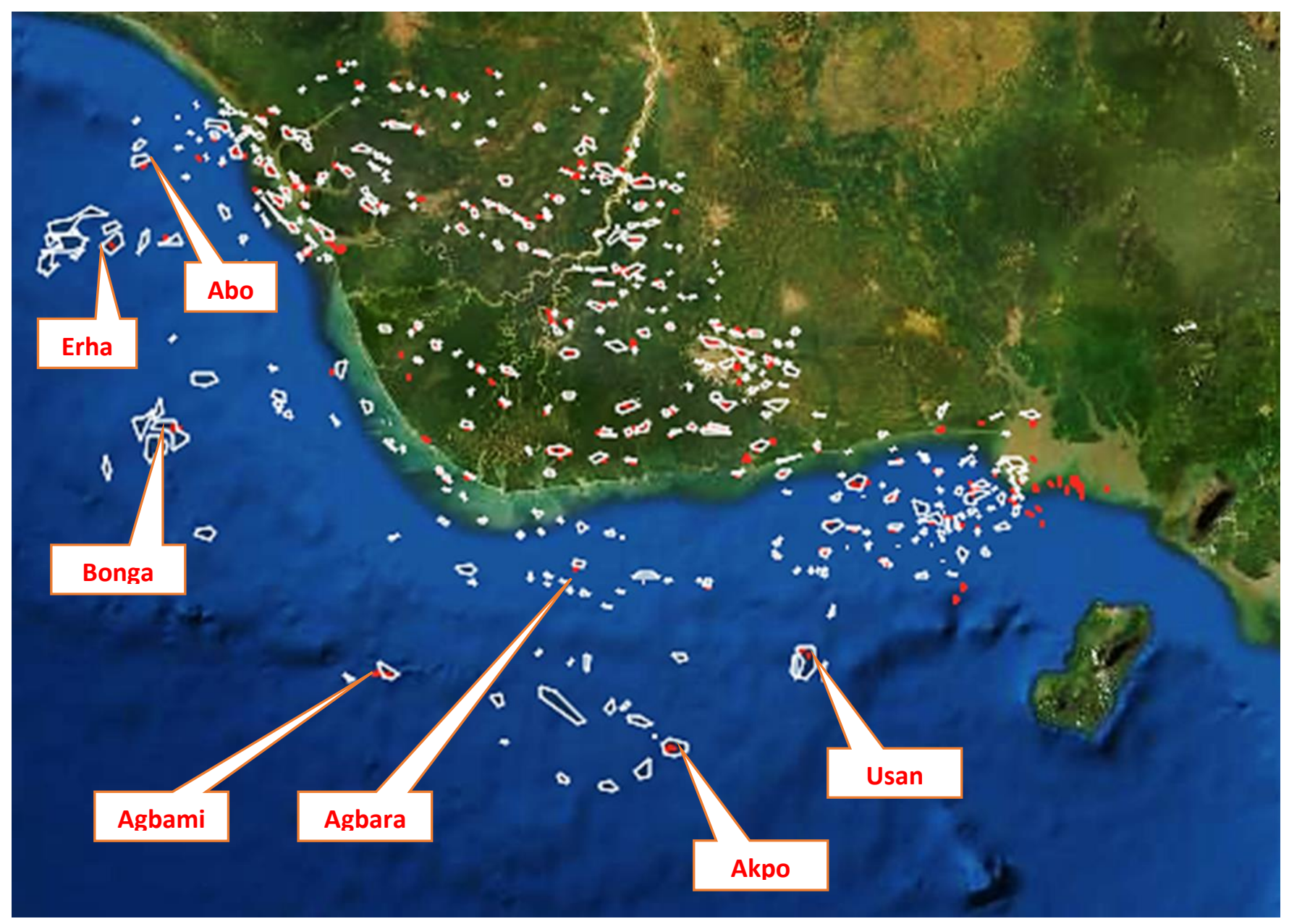

Figure 6: Satellite view of selected offshore fields in the Niger Delta region.

and compare their values with other VNF flare products for consistency.

World Bank and NNPC). It was observed from Figure 7 that Skytruth and the World Bank flare estimates are very similar and most conservative. The DPR estimates show a similar trend but reveal a significant difference of approximately 50 to 100 Billion standard cubic feet (Bscf) across the period of consideration. The NGFT indicates higher cumulative flare volumes from monthly estimates. The NNPC report shows a drastic reduction in flare volumes in the Niger Delta region, although reports from 2018 to 2020 excluded independent and marginal field companies and included Joint Venture (JV) and Production Sharing Contract (PSC) companies. Despite having different trends, all the estimates show a downward trend confirming a gradual reduction of flaring activities in the period of consideration.

In contrast to the conclusion by (Collins, 2018; Lee, 2019; Leyden, 2019), satellite-based flare estimates are significantly greater than state regulatory reports, but in Nigeria, some flare estimates support the contrast. Figure 8 shows offshore oil fields which are considered PSC companies in Nigeria. They are prolific fields and are operated by international oil companies, as shown in Table 1. Due to unavailable satellite data in 2020, the Agbara field was not shown in Figure 8. It was observed that reported flare estimates were higher than the Skytruth estimates in three oil fields (Agbami, Bonga and Usan); with other oil fields showing very close estimates. NGFT estimates were higher in all observations except Agbami, which showed close results with the NNPC report estimates. Hence, for the oil fields considered, similarity exists, which counters the conclusion that estimates from satellites are twice that of reported data as confirmed in the Texas Permian Basin (Leyden, 2019; Collins, 2018). It was also observed that the volumetric ratio of NGFT to Skytruth is within a range of 1.4 to 1.8 , which implies that a linear relationship exists between the two annual satellite-based gas flare volumes sources.

These findings were further investigated and subjected to paired t-test employed to establish the significances of two sets of research questions based on monthly flare volumes from 2016, 2017, 2020, to April 2021. Also, Pearson correlation was used to assess if a possible linear association exists between the NGFT and NNPC flare volume estimates.

\section{Hypothesis question 1}

- H0: Is the mean of the monthly NGFT flare volume the same as the mean of monthly NNPC reported flare volumes? 


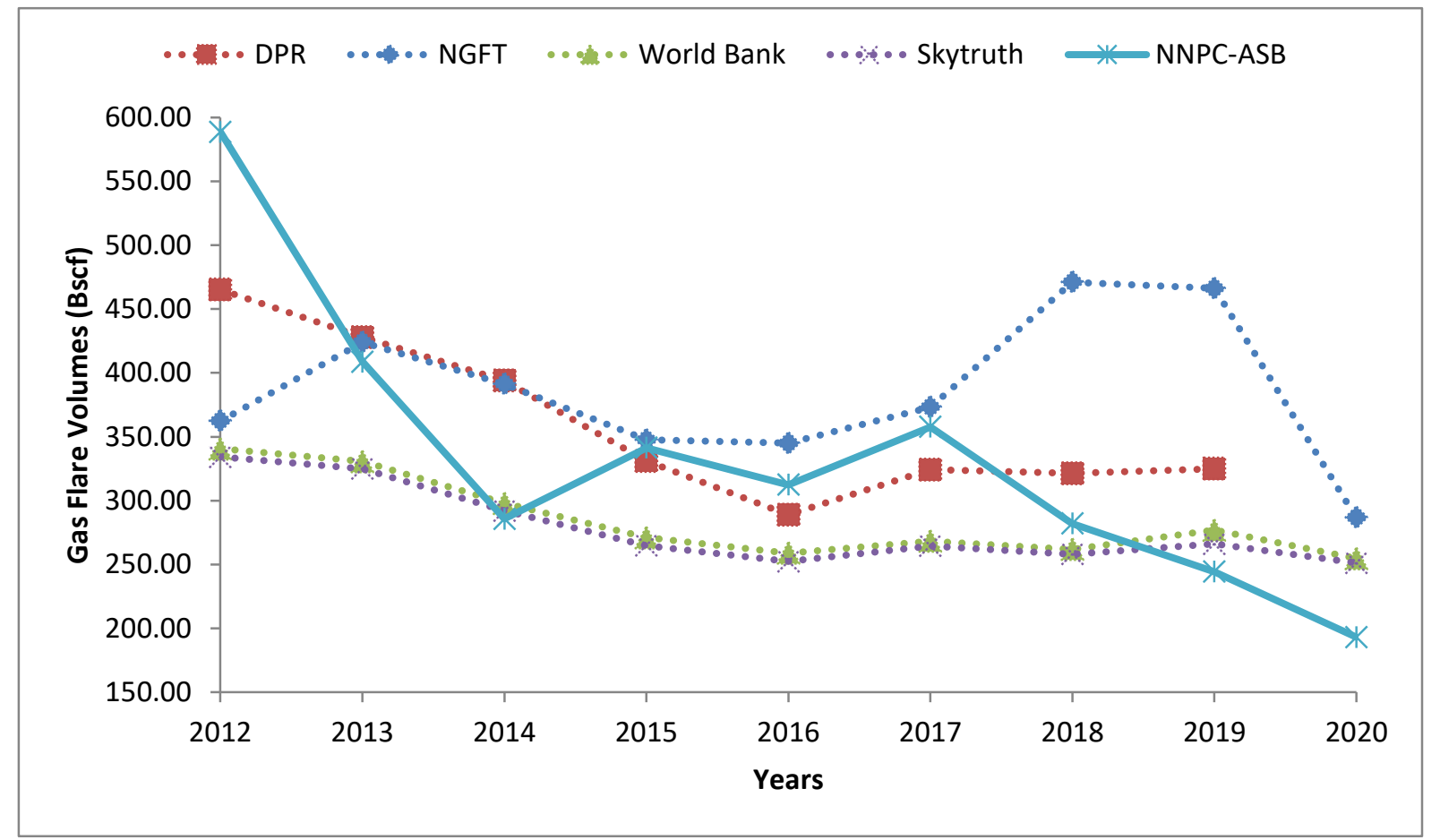

Figure 7: Times series graph of various Nigeria Annual Flare estimates (2012 - 2020).

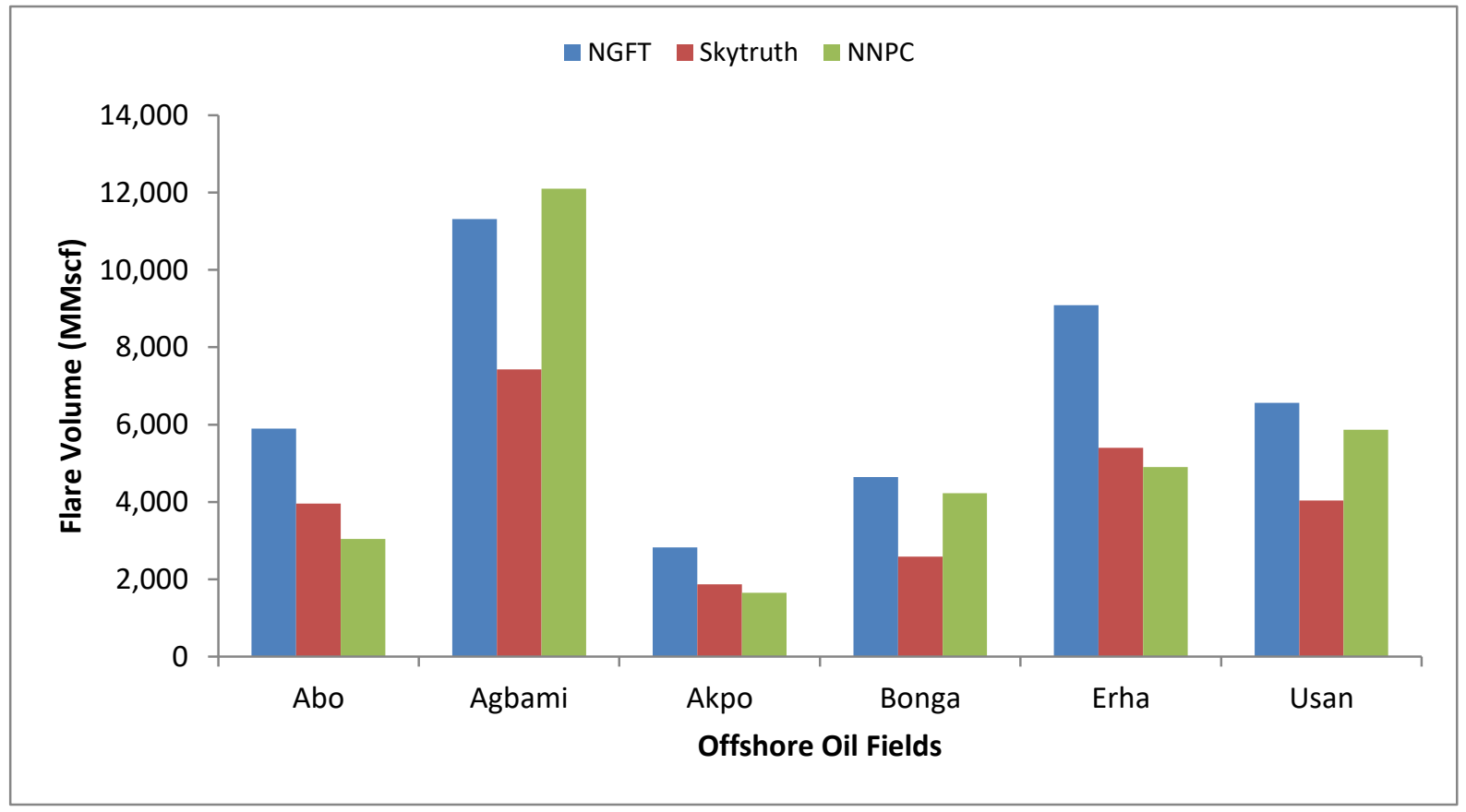

Figure 8: 2020 Annual field flare volume of prolific offshore oil fields in Nigeria based on reports.

- Ha: Is the mean of the monthly NGFT flare volume different from the mean of monthly NNPC reported flare volumes?

2. Hypothesis question 2

- H0: Is the mean of the monthly NGFT flare volume less than or equal to the mean monthly NNPC reported flare volumes?

- Ha: Is the mean of the monthly NGFT flare volume greater than the mean monthly NNPC reported flare volumes? 
Based on the summary result in Table 2, it was observed that 4 of the oil fields, namely Agbara, Bonga, Erha and Usan, failed to reject the null hypothesis for both sets of research questions resulting in an inconclusive inference for the period considered. Abo and Akpo oil fields indicated a difference in the means and that the satellite data was significantly higher than the reported estimates, while Agbami oil fields indicate that the reported data was significantly higher than the satellite estimates $(p=1)$. These results suggest that flare volumes reported in the Niger Delta offshore have varying degrees of flare volume accuracy with satellite estimates. On the other hand, the correlation results reveal that though the monthly reports have a positive relationship, the degree of association is considered "moderately strong" based on correlation coefficient classification (Munson, 2016). This implies that monthly regulatory reports do not obtain the records of gas flaring properly in the region, as flare estimates should result in a very strong degree of association when compared with satellite-based data. Aside from inadequate reporting techniques, another reason is that unaccounted natural gas venting and leakages (predominately methane) are combined with flare volumes and reported as a form of disposal to ensure mass balance.

This fact is evident in the lack of records for venting volumes in the region, considering the fact that venting and leakages contribute significantly to losses in the Natural gas value chain (Capterio, 2020) and is a more potent contributor to global warming (Caulton et al, 2014). utilizing both data sources and adjustable inferences for a more robust monitoring scheme.

\section{REFERENCES}

Anejionu, O.; G. Blackburn and J. Whyatt. (2014). Detecting gas flares and estimating flaring volumes at individual flow stations using MODIS data. Remote Sensing of Environment, 81-94.

Anejionu, O. C.; A. Blackburn and D. Whyatt. (2013). Remote Mapping of Gas Flares in the Niger Delta with MODIS imagery. Towards Horizon 2020.

Brandt, A. R. (2020). Accuracy of satellite-derived estimates of flaring volume for offshore oil and gas operations in nine countries. Environmental Research Communications, $1-12$.

Capterio, (2020). New Flaring Data accelerates Global call to action. Available online at: https://capterio.com/wpcontent/uploads/2020/07/20200722-New-Flaring-Data-

Accelerates-Call-To-Action.pdf. Accessed on January 8, 2021.

Casadio, S.; O. Arino and D. Serpe. (2011). Gas flaring monitoring from space using the ATSR instrument series. Remote Sensing of Environment, 239-249.

Caulton, D. R.; P. B. Shepson, R. L. Santoro, L. Renee, J. P. Spark, R. W. Howarth, A. R. Ingraffea, M. O. Cambaliza, C. Sweeney, A. Karion, K. J. Davis, J. Kenneth, B. H. Strim, S. A. Montzka, B. R. Miller. (2014). Toward a better understanding and quantification of methane emissions from shale gas development. PNAS, 6237-6242.

\begin{tabular}{|c|c|c|c|c|c|c|c|c|c|}
\hline $\mathbf{S} / \mathbf{N}$ & $\begin{array}{c}\text { Oil } \\
\text { Field }\end{array}$ & $\begin{array}{c}\text { Paired } \\
\text { Sample } \\
\text { Size }\end{array}$ & $\begin{array}{c}\text { Paired Mean } \\
\text { Differences }\end{array}$ & $\begin{array}{l}\text { Standard } \\
\text { Deviation }\end{array}$ & $\begin{array}{l}\text { Do the } \\
\text { means } \\
\text { differ? }\end{array}$ & $\begin{array}{c}\text { Is NGFT } \\
\text { greater than } \\
\text { the NNPC } \\
\text { report }\end{array}$ & $\begin{array}{c}\text { Outlier } \\
\text { (Grubb's } \\
\text { test) }\end{array}$ & $\begin{array}{c}\text { Missing } \\
\text { data }\end{array}$ & $\begin{array}{c}\text { Pearson } \\
\text { Correlation } \\
\text { Coefficient }\end{array}$ \\
\hline 1 & Agbara & 23 & -3.2433 & 82.231 & No $(\mathrm{P}=0.852)$ & No $(\mathrm{P}=0.575)$ & 0 & 1 & 0.642 \\
\hline 2 & Abo & 39 & 251.19 & 222.40 & Yes $(\mathrm{P}<0.001)$ & $\begin{array}{c}\text { Yes } \\
(\mathrm{P}<0.001)\end{array}$ & 0 & 1 & 0.619 \\
\hline 3 & Bonga & 33 & -71.430 & 363.84 & No $(p=0.261)$ & No $(\mathrm{P}=0.870)$ & 3 & 4 & 0.377 \\
\hline 4 & Erha & 40 & 75.884 & 480.97 & No $(\mathrm{P}=0.325)$ & No $(\mathrm{P}=0.162)$ & 0 & 0 & 0.311 \\
\hline 5 & Akpo & 36 & 80.677 & 114.32 & $\begin{array}{c}\text { Yes } \\
(\mathrm{P}<0.001)\end{array}$ & $\begin{array}{c}\text { Yes } \\
(\mathrm{P}<0.001)\end{array}$ & 4 & 2 & 0.536 \\
\hline 6 & Agbami & 40 & -970.94 & 1120.6 & $\begin{array}{c}\text { Yes } \\
(\mathrm{P}<0.001)\end{array}$ & No $(\mathrm{P}=1)$ & 0 & 0 & 0.603 \\
\hline 7 & Usan & 38 & -6.3166 & 261.71 & No $(\mathrm{P}=0.883)$ & No $(\mathrm{P}=0.559)$ & 1 & 1 & 0.585 \\
\hline
\end{tabular}

Yes: Reject the null hypothesis, No: Fail to reject the null hypothesis

\section{CONCLUSION}

This research work raised important questions regarding the accuracy and reliability of flare volumes estimates from different sources. It also highlighted the similarity and differentials between VIIRS satellite-based estimates and regulatory-based reports using selected offshore oil fields in the Niger Delta region. This research also creates a case for monitoring natural gas venting operations, which is also a significant contributor to global warming. It is recommended that Regulatory Authorities should adopt a hybrid approach in
Coffey, V. (2012). Multispectral Imaging moves into the Mainstream. Optics and Photonics News, 23(4): 20.

Collins, B. (2018). Are Some Shale Producers UnderReporting Gas? Available online at: https://www.spglobal.com/en/research-insights/articles/aresome-shale-producers-under-reporting-gas-flaring-to-keepoil-flowing. Accessed on May 12, 2021.

Elvidge, C. D.; M. A. Zhizhin, K. E. Baugh, F. C. Hsu and T. Ghosh (2015). Methods for Global Survey of Natural Gas Flaring from Visible Infrared Imaging Radiometer Suite Data. Energies. 1-15. 
Elvidge, C. D.; D, Ziskin, M. A. Zhizhin, K. E. Baugh, F. C. Hsu, T. Ghosh, B. T. Tuttle, D. W. Pack and E. H. Erwin (2009). A Fifteen Year Record of Global Natural Gas Flaring Derived from Satellite Data. Energies. 595- 622.

GGFRP. (2016). Gas Flaring Definitions. Available online http://www.worldbank.org/en/programs/gasflaringreduction\# 7. Accessed on April 2, 2019.

Hodgson, R. (2018). Generating a scalable calibration equation that can be applied to VIIRS Nightfire (VNF) radiant heat calculation to estimate gas flaring volumes in Nigeria, Birkbeck, United Kingdom.

JPSS, (2021). Joint Polar Satellite System. Available online at: https://www.jpss.noaa.gov/mission_and_instruments.html. Accessed on May 28, 2021.

Lee, R. (2019). Does Self-Reporting Measure Up? Environmental Misreporting in the Bakken. Available online at:

https://www.dropbox.com/s/lxzsnsoogefsdyd/RuiwenL ee_JMP.pdf?dl=0. Accessed on May 12, 2021.

Leyden, C. (2019). Satellite Data Confirms Permian Gas Flaring Is Double What Companies Report. Available online http://blogs.edf.org/energyexchange/2019/01/24/satellitedata-confirms-permian-gas-flaring-is-double-whatcompanies-report/. Accessed on May 12, 2021.

Munson, L. (2016). Statistical Insights: Microsoft Professional Program. Microsoft.

Mylvaganam, K. (1989). High-Rangeability Ultrasonic Gas Flowmeter for Monitoring Flare Gas. IEEE Transaction on Ultrasonics, Ferroelectrics and Frequency Control, 36(2): 144-149.
NASA. (2015). A Clearer View of Fire. Available online at: https://earthobservatory.nasa.gov/images/87111/a-clearerview-of-fire. Accessed on May 24, 2021.

NASA. (2018). JPSS Concept of Operations: Constellation Management. Available online at: https://svs.gsfc.nasa.gov/4613. Accessed on November 19, 2020.

Ndunagu, U. P. (2021). Flaring Intensity approach to Gas Flare Monitoring and Utilisation in the Niger Delta. Unpublished P.hD dissertation, University of Port Harcourt, Nigeria.

Sharma, A.; J. Wang and E.M. Lennartson. (2017). Intercomparison of MODIS and VIIRS Fire Products in Khanty-Mansiysk Russia: Implications for Characterizing Gas Flaring from Space. Atmosphere, 8(6): p. 95.

Willyard, K. A. and Schade, G. W. (2019). Flaring in two Texas shale areas: Comparison of bottom-up with topdown volume estimates for 2012 to 2015. Science of the Total Environment, pp. 243-251.

World Bank. (2019). Global Gas Flaring Data. Available online at: https://www.ggfrdata.org/. Accessed on January 4, 2021.

World Bank. (2020). Estimation of Flare Gas volume from satellite. Available online at: http://pubdocs.worldbank.org/en/853661587048977000/Esti mation-of-flare-gas-volumes-from-satellite-data-002.pdf. Accessed on November 23, 2020.

World Bank. (2021). Zero Routine Flaring by 2030. Available online at: https://www.worldbank.org/en/programs/zero-routineflaring-by-2030. Accessed on May 9, 2021.

Zhang, Y. et al. (2019). Satellite-Observed Changes in Mexico's Offshore Gas Flaring Activity Linked to Oil/Gas Regulations. Geophysical Research Letters. 1-10. 